Fecha de recepción: diciembre 2017 Fecha de aceptación: marzo 2018 Versión final: julio 2019

\section{Escrevendo cartas, produzindo tipos e edificando o todo. A escrita na Companhia de Jesus, entre seus membros: uma escritura que seja edificante ${ }^{1}$}

Marcelo Augusto Maciel da Silva *

\begin{abstract}
Resumo: Este trabalho se propõe a examinar a prática de escrita de Pedro Lozano, um jesuíta que também exerceu a função de historiógrafo na Companhia de Jesus, em meados do século XVIII. O exercício foi realizado a partir de uma missiva por ele destinada ao Procurador Geral, Pe. Bruno Morales. Sabe-se que a documentação produzida pelos inacianos possui reconhecido valor histórico e etnográfico sendo, por isso, intensiva e extensivamente explorada pelos acadêmicos, assim como por escritores literários. A análise sobre esse tipo de fonte também permite tomar por objeto a prática de escrita desses indivíduos, sobretudo, a partir da reflexão sobre seu "lugar de produção", bem como sobre a "operação historiográfica" nela empregada, conforme sugeriu Michel de Certeau. Desse modo, não ignorando a existência de uma individualidade na escrita de Lozano, definiu-se -para circunscrever o lugar de onde ele escreve, bem como delimitar a atividade escriturária em si- delinear os limites impostos pela Ordem a partir do exame das Reglas de la Compañia de Jesús, das Constituciones e da autobiografia de Santo Inácio de Loyola. Coadjuvantes no relato de acontecimentos reais, e fazendo uso de uma representação cuja constante era a tensão social, organizava-se um discurso desenvolvido a partir de reiteradas orientações. Estas, expressadas nas cartas e supostamente obedecidas, ao tornar-se prática de leitura e de escrita, ao passo que informavam, também conformavam. Edificavam uma imagem institucional, ao mesmo tempo em que se elaboravam a si. O texto contribuía para a instrução, mas também resultava na construção de seu próprio autor. Se os edificavam, também os identificavam, podendo-se conhecer a Ordem pelo indivíduo, e ao mesmo pelas práticas.
\end{abstract}

Palavras chaves: Lugar de produção - Jesuítas - Prática de escrita.

[Resumos em espanhol e inglês na página 125-126]

${ }^{(*)}$ Licenciado para o ensino de História pela Universidade do Vale do Rio dos Sinos (UNISINOS), também é Mestre em História Latino-americana pelo Programa de Pós-Graduação da mesma universidade. Tem experiência com a pesquisa histórica, atuando principalmente sobre os seguintes temas: sociedades indígenas, cativos, e fronteiras. E-mail: marceloaugustus@msn.com 


\section{Introdução}

Este trabalho se propõe a examinar uma carta de 01 novembro de 1746, remetida pelo padre Pedro Lozano ao Procurador Geral da Companhia de Jesus, Bruno Morales. Na ocasião, discorreu sobre os acontecimentos recentes, contemplando exaustivamente a situação das fronteiras meridionais das gobernaciones do Rio da Prata e do Paraguai. Assim, destacava os conflitos, versando sobre os ataques ocasionados pelos indígenas e as "decorrentes punições" empreendidas pelos hispânicos. Além disso, a missiva trazia outras informações, relacionadas às dificuldades e sucessos do trabalho missionário.

Nascido em Madrid em 1697, Lozano ingressou na Companhia de Jesus em 1711, chegando a Buenos Aires em 1714. Tornou-se o historiógrafo da referida Ordem apenas em 1730, ocupando o cargo até o seu falecimento, em 1752. Além de ter escrito obras contemplando a história da Província do Paraguai e da própria Companhia de Jesus, teve por obrigação do cargo a responsabilidade de redigir informes às instâncias superiores, de modo a atualizá-las sobre os acontecimentos ocorridos na colônia. Ademais, possui uma vasta produção composta por trabalhos de tradução e biografias, entre muitos outros tipos de registros como informes, documentos jurídicos e cartas ânuas (Cargnel, 2007, p. 317).

Junto à missiva que Lozano enviava ao Procurador, anexavam-se duas sínteses de outras correspondências que ele havia recebido anteriormente e agora as encaminhava, assim como fazia com a cópia de um diário referente a uma expedição ao Estreito de Magalhães, além da duplicação de outra carta relativa à missão de Nuestra Señora de la Concepción de los Pampas. Tendo em vista que a cópia e as demais sintetizações que realizou apenas reproduzem um conteúdo, toma-se como objeto de análise aquilo que faz da epístola uma produção textual autoral de Lozano, isto é, o "prólogo" que precede às anexações. Assim, o que se segue,toma os seus dizeres apenas como dados complementares de um discurso; já o que interessa são os objetivos de seu texto, que não necessariamente propunha-se apenas a narrar os fatos.

Embora a produção bibliográfica de Lozano não tenha se restringido a livros propriamente ditos de História, pode-se dizer que ao narrar acontecimentos e tecer comentários sobre os mesmos, ele elaborava interpretações e consequentemente "fazia a história". Desta forma, como resultado de uma construção de inteligibilidade sobre dados históricos, seus escritos são, também, uma contribuição à historiografia colonial, e como tal, passível de análise através da "operação historiográfica" (Certeau, 2015, p. 45-111). Logo, busca-se compreender, primeiramente, o "lugar de produção" em que se encontrou e pelo qual se constituiu Pedro Lozano para, então, refletir sobre o procedimento historiográfico orientado pelas normas da Companhia, para, por fim, abordar o texto por ele realizado.

O referido aporte teórico possibilita pensar as narrativas históricas como um discurso ligado a certas operações e definidos por funcionamentos específicos. Desse modo, a escrita, por um lado, uma vez lida torna-se instrumento de ação, por outro, uma vez encerrada apresenta-se um produto que, questionado como objeto, deixa escapar os vestígios de um lugar, de práticas e uma intenção de sentido no discurso. Deste modo, ao inquirir o texto de Pedro Lozano,com o intuito de averiguar seus posicionamentos, busca-se encontrar as marcas do lugar que o precedia, como também os vestígios das práticas imbricadas em seus procedimentos, além da representação do mundo que fazia. 
A abordagem de uma determinada história, sob a compreensão de que esta resulta da articulação de um lugar social de produção, procedimentos de análise, e um texto (Certeau, 2015, p. 46-47) nos leva a examinar-mesmo que de modo limitado-, o lugar em que se inscreveu Pedro Lozano a partir de algumas diretrizes da Companhia de Jesus. Sendo assim, para complementar a reflexão sobre esse "lugar" de onde ele escreve, examinou-se a autobiografia de Inácio de Loyola, as Constituciones, e as Reglas de La Compañia, documento através do qual se procurava definir comportamentos adequados, práticas devocionais, bem como as atividades de cada membro da Ordem, de acordo com as funções e cargos a serem ocupados. Enquanto as duas primeiras foram produzidas pelo fundador da instituição, ainda que compiladas muitos anos depois, o Reglas de La Compañia reúne um conjunto de orientações distintas procedentes também de outros autores.

\section{A Companhia como um lugar}

Ao examinara produção e a troca de correspondências entre os membros da Companhia de Jesus, a partir de sua fundação e ao transcorrer do século XVI, Fernando Torres Londoño apontou para a existência de um sistema de informações "destinado a ajudar na tomada de decisões e na realização de ações" (2002, p. 30). De acordo com o autor, a comunicação se dava em dois sentidos, e a troca de cartas serviu como suporte para um sistema de decisões, no caso, hierárquico e vertical (Londoño, 2002, p. 15). Desta forma, tinha o caráter de governo, pois através delas, o padre Geral e os provinciais se informavam sobre as particularidades de cada região e área de atuação, de modo que, assim, sobre cada um pudessem delegar. Não obstante, as trocas de cartas também ocorriam em sentido horizontal, entre as casas e províncias, a fim de promover a edificação mútua (Londoño, 2002, p. 14). De acordo com Londoño, "o objetivo fundamental de qualquer carta era a união em torno da procura da vontade de Deus" (2002, p. 17). Isto é, que através de um amplo conjunto de informações, pudessem reconhecer os desígnios de Deus para a instituição, Seu propósito para com a atuação dos membros da Companhia. A edificação, portanto, significava entender a missão, além de elaborar a construção de uma imagem pela qual pudessem se adequar, bem como orientar terceiros. Buscava-se uma representação para o quê a Ordem queria se tornar, como também se elaborava a aparência com a qual ela devia se apresentar. Também Viviane São Bento (2015) afirma que as correspondências trocadas entre os religiosos tinham o propósito de esclarecer aos seus superiores as condições locais às quais os missionários se encontravam expostos. "Os jesuítas enviavam informações e esperavam de volta instruções para serem ajustadas à situação local” (São Bento, 2015, p. 3). Deste modo, qualquer que fosse a notícia, antes de tudo, ela deveria corroborar para a formação da instituição e de seus indivíduos. A edificação moral era a "marca geral dos registros jesuíticos, fossem eles catecismos, cartas edificantes, crônicas ou histórias" (Tavares, 2005, p. 9). Para ser edificante, o texto necessitava, portanto, fornecer informações como a quantidade de confissões, as pregações, bem como os atos que os inacianos considerariam notáveis (Londoño, 2002, p. 21). Segundo Fernando Londoño, nos anos cinquenta do século XVI, inclusive, esse modelo de cartas cujo conteúdo era considerado edificante já havia se consolidado entre os inacianos (2002, p.23). 
Além da carta examinada nesse trabalho, os jesuítas produziram uma outra, de tipo bem específico, intitulado Carta Ânua. Ambas cumpriam o propósito de prestar informações aos superiores da Companhia. As Ânuas eram redigidas pelos membros da Companhia que ocupavam cargos de secretários do Superior de Província. No entanto, também podiam ser produzidas por outras pessoas, desde que nestas, fosse reconhecido talento para escrever. Seu redator devia reunir os conteúdos das muitas correspondências recebidas dos demais membros da Companhia que estavam dispersos -fosse em escolas ou em reduções- e compilá-las em um único expediente. Além disso, constavam dados provenientes de visitas realizadas pelo Superior aos estabelecimentos da Ordem, em sua jurisdição. Encerrado o processo, as epístolas eram remetidas ao Procurador Geral da Companhia de Jesus, em Roma (Fleck; Franzen; Martins, 2008, p. 9-14).

Essas cartas que, embora levassem o nome -e se pretendessem-, como anuais, poderiam levar anos até que fossem concluídas, uma vez que o recebimento das missivas que vinham do interior da colônia podia atrasar. Até porque, antes de serem enviadas ao Procurador Geral, elas eram submetidas a um censor, depois, à avaliação de Consultores de Província, e, por fim, transcritas ao latim (Fleck; Franzen; Martins 2008, p. 9-14). Em todo caso, as correspondências seguiam uma rígida classificação e um ordenamento que visava selecionar o que era tido por importante e conveniente, bem como excluir aquilo que não fosse positivo para os leitores. É preciso ressaltar que não apenas os jesuítas consumiam seus escritos, motivo pelo qual o conteúdo edificante devia alcançar também os leitores que não se relacionavam diretamente com a Ordem. Como a divulgação dos textos inacianos também se dava entre a elite culta europeia, sua circulação entre os leitores que não eram membros da Companhia procurava fomentar a boa vontade das autoridades, atrair a doação de bem feitores, bem como estimular a vocação de novos irmãos (Fleck; Franzen; Martins, 2008, p. 9-14). Josefina Cargnel, por exemplo, diferencia as crônicas das correspondências internas, alegando que enquanto estas últimas eram de circulação apenas entre os membros da instituição, enquanto as primeiras tinham recepção em um público mais amplo (2009, p. 299).

Assim como nas Ânuas, os demais escritos realizados por estes religiosos seguiam orientações precisas evidenciando um conjunto de normas, bem como a existência de um limite ao conteúdo a ser relatado, que como afirmou Maria Cristina Bohn Martins (2014, p. 236), também são produto de uma dada visão compartilhada pelos padres. Em Cargnel (2009, p. 298), vemos a autora afirmar que a escrita foi fundamental para que o poder disciplinar da Companhia pudesse ser global e contínuo. A autora afirma que desde as primeiras cartas, e mais incisivamente a partir das Reglas, não somente a vida, mas também a forma com que se devia escrever foram minuciosamente regulamentadas a fim de gerar estratégias de governo e coesão, bem como a representação que da Ordem se constituía (Cargnel, 2009, p. 299).Ao examinar as crônicas de Lozano e de Guevara, Josefina Cargnel afirmou que se tratavam de obras similares, uma vez que o espírito que demonstravam era o da Ordem a que pertenciam, assim como também compartilhavam o método dos cronistas de sua época $(2009$, p. 303). 


\section{A escrita como produto, um elo entre o ser e o seu lugar}

Ao se abordar a Companhia de Jesus como lugar de produção de um modelo específico de escrita, estamos indiretamente atribuindo esse conteúdo como resultante, também, de indivíduos que se supõe compartilhando hábitos e comportamentos em comum. Sendo assim, existem indícios que poderiam nos apontar o tipo de indivíduo que se almejava consolidar? É possível conjecturar qual seria a conduta esperada de um jesuíta? Senão em sua totalidade, alguns direcionamentos parecem sugerir que sim.

Através do exame do escrito autobiográfico pode-se dizer que o teor das orientações nele contidas visava estabelecer parâmetros de virtude que deveriam ser tomados como modelo pelos membros que ingressavam na Ordem. Ao decorrer do texto, várias passagens fazem alusão: à importância de se manterem perseverantes; à necessidade de praticar bons pensamentos a fim de vencer as tentações; e, também a uma disciplinada prática de estu$\operatorname{dos}^{2}$ e escrita.

Além disso, o exercício de escrever articulado às orientações possibilitava alcançar elevado grau de obediência e submissão. Assim se mostra a passagem da autobiografia, onde Santo Inácio relata o início de sua jornada espiritual. Segundo ele, antes mesmo de sua peregrinação à Jerusalém, habitualmente "perseveraba en su lección" sendo que, "Parte del tiempo gastaba en [sic] escribeir, parte en oración” (Loyola, [1553-1555], cap. I, § 8). Loyola destacava que, mesmo quando não tinha "conocimiento de cosas interiores espirituales” (Loyola, [1553-1555], capítulo III, \$20) encarara uma luta contra aborrecimentos oriundos de pecados passados que não cessavam, mas que uma vez vencidos tornara-se "bueno escribirse" (Loyola, [1553-1555], cap. II, §14-18).

A importância destinada a um certo tipo de escrita também é nítida ao se observar a composição das Reglas. Nesta, encontra-se expressiva e reiteradamente a exaltação à obediência, claramente vinculada, senão decorrente, da leitura de conteúdos em comum e que contribuiria para os edificar. Através dessas repetitivas orientações que deveriam ser lidas por todos -em alguns casos voltadas apenas ao ocupante de um determinado ofício-, Santo Inácio de Loyola buscava conservar um modus operandi ao mesmo tempo em que constituía uma identidade relativamente homogênea para a imagem do grupo. Para tanto, as correspondências serviam às necessidades de se manter um conhecimento mútuo entre os jesuítas mesmo que estes se encontrassem distantes -conforme se distribuíam os membros da Ordem (Wucherer, 2013, p. 146).

Desde o início, ao fundador da Companhia de Jesus importava escrever sobre bons exemplos de devoção com intuito de edificar a própria fé, bem como a de seus possíveis leitores e correligionários. Ao se referir a inquietação que culminou na decisão de abandonar seus pertences para vestir-se das armas de Cristo, Loyola justificativa o voto de pobreza (REGLAS, p. 11, § 23-25). Sobre isto, as Reglas impunham precisas obrigações para cada membro que lidasse com doações em geral. Também os "exercícios espirituais" eram importantes de serem redigidos para edificação dos membros da Companhia e de fiéis. Ao longo de seu testemunho de vida, Santo Inácio salienta muitas vezes o quão benéfico era seguir os exercícios que havia desenvolvido a partir de "algunas cosas que observaba en su alma y las encontraba útiles" e que poderiam "ser útiles también a otros", motivo pelo qual "las ponía por escrito" ([1553-1555], cap. XI,\$ 99). 
Se o testemunho redigido na autobiografia não era suficiente para estimular a edificação das almas, em Reglas reiterava-se a necessidade de uma constituição cujo intuito era ajudar no melhor proceder do divino serviço (REGLAS, 1735, p. 4, \$1.). Além de dispor sobre as práticas confessionais, outra orientação contida nas Reglas afirma que cada um que entrasse na Companhia, seguindo o conselho de Cristo "haga cuenta de dexar el Padre, y la Madre, y hermanos, y hermanas, u quanto tenia en el mundo" (REGLAS, 1735, p. 6, §8). A Companhia se pretendia uma grande família cristã que, como tal, mesmo hierarquizada buscava desenvolver sentimentos de unidade por afinidades.

Para um grupo que se busca exemplo de conduta cristã,demonstrava-se pertinente suscitar em seus membros a transparência sobre seus atos, de modo a dar exemplo de reta conduta, bem como colocar-se diante do policiamento de seus "irmãos". Desse modo, estimulava-se que se "cuidassem uns aos outros", admoestando que todo erro, falta, ou qualquer coisa que se notasse e soubessem fossem "manifestadas á sus Mayores, por qualquiera persona, que fuera de confessión las supiere" (REGLAS, 1735,p. 6, $\$ 9)^{3}$. Havendo concordância quanto ao engrandecimento espiritual e moral através do acompanhamento da edificação de uns pelos outros, buscava-se aparar as arestas e construir um sentimento de unidade. Considerando a dificuldade que -devido à dispersão-, tinham os membros da Companhia para nutrirem um espírito de união, fato reconhecido no capítulo primeiro (Loyola, 1599, Cons 8: 655) da oitava parte das Constituciones, e reconhecendo como necessária que isto se concretizasse, registra o dispositivo da lei, que tal sintonia se alcançaria em "gran parte con el vínculo de la obediencia" (Loyola, 1599, Cons 8: 659) e "guardada la subordenación mantedrá la unión que muy principalmente en ella consiste, mediante la gracia de Dios nuestro Señor" (Loyola, 1599, Cons 8: 662). Nas Constituciones a comunicação entre as lideranças e seus membros são tidas por convenientes (Loyola, 1599, Cons 8: 668), "specialmente [sic] la communicación de missivas entre los inferiores y Superiores [...] dando orden cómo em cada parte se pueda saber de las otras lo que es para consolación y edificación mutua en el Señor nuestro" (Loyola, 1599, Cons 8: 673).

De fato, não é possível mensurar, se ou o quanto, a obediência dos padres da Companhia costumava ser praticada conforme o solicitado nas Reglas - isto é, se estavam "acostumbradose à no mirar quien es la persona à quieno bedecen, sino quien es aquel por quien, $\mathrm{y}$ à quienen todos obedecen, q es Christo" (REGLAS , 1735, p. 16, \$38). Entretanto, pode-se supor a existência de um alto grau de observação das normas, mesmo que algum tipo de falta já fosse esperado. O descumprimento das normas estava previsto pela Ordem, pois,sugeria-se que uma vez ao ano, "todos ruegen al Superior, les mande dar penitencias, por la falta de observar lasreglas” (REGLAS, 1735, p. 21, \$51).

Assim, os membros da Companhia de Jesus submetiam-se a um grau, ao menos simbólico, de obediência e submissão, que nos leva a supor que os indivíduos que compuseram a Ordem cumpriam -com provável relativa autonomia-, pelo menos uma desejável aparência de conformidade em relação aos preceitos redigidos. Desse modo, o lugar de onde fala o Pe. Lozano apresenta-se, tanto a seus colaboradores quanto ao público externo, como subordinado a Deus e constituído por homens praticantes de hábitos edificantes e dotados de valioso conhecimento intelectual e moral cuja subserviência e disciplina os dignificava para o trabalho missional. Assim, no que concerne à observância dos limites em relação à imagem a ser representada pela escrita na instituição, sugere-se que eram habitualmente 
respeitados. Ademais, que Pe. Lozano e os demais religiosos compartilhavam práticas e hábitos, quando não em comum, bem especificadas nas Reglas ou nas Constituciones.

\section{A escrita como prática, o edificante e o não dizível}

Como se destaca, para a Companhia de Jesus, a escrita era um meio; e o escrito, além de instrumento, tinha fim em si mesmo. Ao mesmo tempo em que o texto era produzido para a elaboração de um membro de tipo exemplar, também era formulado com vistas a desenvolver um testemunho positivo e homogêneo para a imagem que a Companhia queria construir e representar. Neste sentido, através da escrita se edificava a instituição, seu representante e um testemunho.

O cuidado com o escrito mais uma vez revela-se pelas Reglas, quando ao dispor sobre o trato com pessoas de fora da Companhia, impõe que "Ninguno dè cuenta à los de fuera de lo que en casa se haze, òse ha de hazer, sino entendiese que el Superior lo tiene por bien ni tampoco les comunicara las Constituciones, ni otros libros, ò escritos, que traten del Instituto de la Compañia" (REGLAS, 1735, p. 28-29, \$ 38). E assim, uma vez que se fazia necessário muitas deliberações do Superior, também a censura se tornava implícita ao determinar a fronteira que separa o edificante do não permitido; além de legitimar àquele que podia falar. Desse modo, determinava-se que "Ninguno tenga libros sin licencia" $(R E-$ GLAS, 1735, p. 23, \$ 8); e além do mais, "Ninguno de los que fe reciben para Coadjutores temporales aprenda, à leer, ò escribir, ni outro alguno se lo enseñara, sin licencia de el Prepósito General" (REGLAS,1735, p. 23-24, §14).

Há de se considerar que a rigidez da Ordem se devia ao seu pragmatismo, cuja eficiência se buscava através da distribuição de cargos com responsabilidades precisas. Ao se esperar que pelo comportamento obediente se articulasse o bom funcionamento dessa estrutura, recomendava-se que "no considereis la persona de el Superior, como hombre sugeto à errores" (REGLAS, 1735, p. 60). Sobre estas disposições para com “os outros" ressaltava-se que "las hagan familiares, y refresquen la memoria de ellas, leyendolas, ò oyendolas leer cada mês" (REGLAS, 1735, p. 31, $\$ 49)$. Antes de tudo, deveria ser valorizado aqueles escritos que "parecieren mas a proposito para su aprovechamiento espiritual" (REGLAS, 1735 , p. 81, \$10).

Este regime de escrita, também se mostrava objetivo ao ordenar a existência de um arquivo para as escrituras originais, bem como estava em conformidade com a Companhia no que concerne à necessidade que tinham pela grande quantidade de trocas de correspondências. Como mencionado no início deste trabalho, uma vez que o Procurador Geral da instituição tivesse conhecimento o mais completo o possível sobre as situações e calamidades por que passavam os sacerdotes da Ordem -mesmo não sabendo em que lugar do mundo se encontrassem-, "podría guiarlos y gobernarlos en el servicio de su Señor y de sus hermanos" (Wucherer, 2013, p. 147).

A importância dada aos textos, bem como aum tipo específico de escrita praticada pelos jesuítas se evidencia pelo fato de que também pelas Constituciones estas atividades foram regulamentadas. No documento, acerca das práticas de leitura, estava sentenciado que "En los libros de Humanidad étnicos no se lea cosa deshonesta” (Loyola, 1599, Cons 4:359 E), 
e nos Colegios "se leerán que en cada facultad se tuvieren por de más sólida y segura doctrina, sin entrar en alguno que sean suspectos ellos o sus auctores" (Loyola, 1599, Cons 4: 464). E caso se trata-se de um livro sem suspeita de má doutrina, mas cujo autor fosse suspeito "no conviene que se lea, porque se toma affición por la obra al auctor" (Loyola, 1599, Cons 4:465A). Delimitando o escopo de leitura dos membros da Companhia, agregava-se a recomendação: "Acerca de los libros de Humanidad latinos o griegos escúsese también en las Universidades como en los Colegios, quanto será possible" (Loyola, 1599,Cons 4: 468). Assim como também se impunha que "no haya nadie de publicar libro alguno sin examinación y aprobación special del Prepósito General” (Loyola, 1599, Cons 4: 391). O texto regimental ainda estipulava prazos para escrita, e produção de cópias com vistas a circularem em outras províncias, determinando, inclusive, a duplicação para outros idiomas dentre eles o latim. Contudo, a estas epístolas alertava-se que "contenga solamente las cosas de edificación" (Loyola, 1599, Cons 8: 67 5). O filtro tornava-se mais nítido ao regulamentar que "las cosas que se han de scribir [sic] de más importancia, y las instrucciones de los que se imbían a una parte y otra, podrían conferirse con los tales antes que se scribiesen [sic]; y lo que les parecieses, podría el Secretario mostrarlo al Superior, y lo mesmo en las cosas de doctrina" (Loyola, 1599, Cons. 9: 804). O censo logo se encontra estabelecido devido ao limite do que poderia ser tornado público. Se o seu conteúdo não fosse considerado edificante, ou se o texto ou autor estivessem sob suspeita, não deveria ser registrado.

Assim, entende-se que é desse lugar de obediência e resignação que fala Lozano, sendo, portanto, deste ambiente que se constitui as referências para sua interpretação histórica e sua forma de escrita. E, considerando "impossível analisar o discurso histórico independentemente da instituição em função da qual ele se organiza"(Certeau, 2015, p. 55), concordamos com as contribuições de Michel de Certeau quando afirmou que "Sem esperar as denúncias do teórico o texto assume, ele próprio, sua relação com a instituição (2015, p. 55). Mas se o membro da Ordem, no caso do leitor, era quem se buscava informar para o adequar; o que se propunha àquele que do texto foi escritor? Estava o produtor de missivas isento do alcance do conteúdo de seu trabalho?

Em suma, a Ordem inaciana como "lugar de produção" utiliza a escrita como meio para a criação de uma homogeneidade à qual pudessem se adequar os membros de Companhia. Nesta condição, Josefina Cargnel (2010, p. 110), por sua vez, nos apresenta, além da instituição, um imaginário coletivo próprio do espaço rio-platense. Ao se adequar às orientações prevista, o escritor jesuíta tornava-se,pela obediência e repetição, produto de sua própria escrita, além de ratificar o que seria tido por edificante, e desta forma condicionar os sujeitos que os liam. Assim, desde os textos normativos às correspondências internas, os escritos ratificavam a norma e o comportamento adequado, moldando seus membros em uniformidade com a imagem dainstituição.

\section{A missiva de Lozano, o historiador}

A partir do reconhecimento da Ordem inaciana como o lugar de produção de onde escreve Lozano, e entendendo a escrita como parte constitutiva tanto da imagem da Companhia, 
como da própria identidade de seu ser, constatou-se a existência de diretrizes para um determinado tipo de comportamento, ao mesmo tempo ratificado e reificado pelo texto, a partir de uma determinada prática de escrita. Sendo assim, o exame sobre a correspondência redigida pelo historiógrafo tem o propósito de averiguar sua sintonia com as orientações da Companhia, através de vestígios indicativos de seu tipo de operação textual. Ao observar as correspondências de padre David Fáy, por exemplo, os autores Beatriz Dominguez e Breno dos Santos, identificaram, para meados do século XVIII, "fortes indícios de penetração de alguns aspectos do pensamento ilustrado no seio da Ordem” (2009, p. 239). Com isso, os autores puderam refutar afirmações depreciativas em relação à formação intelectual dos inacianos. No caso de Lozano, o que essa carta revela de seu autor?

Após cumprir as devidas formalidades de uma correspondência colonial ${ }^{4}$, Lozano aborda a fronteira de Salta, aonde milícias espanholas vinham realizando sucessivas perseguições aos indígenas. No entendimento do jesuíta, o empreendimento era bem-sucedido, uma vez que tornava seguro os caminhos que antes eram perigosos, porém, agora "pueden andar mugeres solas por donde antes no se atrevian hombres armados" (Lozano, 1746, p. 1-2). Satisfeito, ele prossegue afirmando o quão bem-sucedidas haviam sido, também, as investidas realizadas por esses milicianos na fronteira de Santiago del Estero. Sobre estes acontecimentos, Lozano relata que o tenente de governador Don Francisco Barreda"anduvo tan genroso, que no quiso tener parte en el botín, sino que todo le repartió entre sus pobres Soldados [...] que quedaron con ansias de hacer outra campaña con él mismo" (Lozano, 1746, p. 3).

O pensamento de Lozano está claramente fundamentado na dicotomia colonial da civilização x barbárie. Segundo ele, quando os nativos realizavam suas invasões era para "continuar sus maldades" (Lozano, 1746, p. 3). Não obstante, o mesmo ocorresse por parte dos espanhóis, tratar-se-ia apenas de um "azote tan merecido" (Lozano, 1746, p. 2). Enquanto o sucesso dos indígenas se devia à uma suposta condição de barbárie, do lado espanhol os vencedores das batalhas eram vistos comopessoas "de mucho valor" (Lozano, 1746, p. 4). Josefina Cargnel já havia situado o trabalho de Lozano como herdeiro da historiografia eclesiástica do século XVII, ressaltando acertadamente que sua obra revelava alguns elementos característicos do pensamento do século XVII, a saber, uma historiografia que apresenta "las divisiones de la humanidad como obstáculos para la marcha de la civilización” (2010, p. 99).

Ao longo da investigação evidenciou-se variadas disposições sobre seus contemporâneos. Um dos grupos a que se refere, por exemplo, é o de soldados milicianos. Todavia, mesmo exaltando os feitos destes espanhóis, o jesuíta não menosprezava que "no por esso dexa de ser grande el sobresalto de los caminantes en todos estos caminos” (Lozano, 1746, p. 4) devido ao fato de que os Soldados vecinos ao "no tirar sueldo no se pueden mantener de contínuo en campaña, siendoles forzoso atender en sus casas à buscar el sustento, con que passar la vida" (Lozano, 1746, p. 4). Sabe-se que estes indivíduos, recrutados à força e sem pagamentos, costumavam ser convocados das áreas fronteiriças aos territórios aborígenes (Mayo, 1998, p. 52-64). Logo, habitantes de áreas rurais, e geralmente pouco instruídos. Através da citação acima, Lozano relata um evento ocorrido e aponta uma fragilidade; o patrulhamento de soldados aparece como um paliativo à falta de segurança dos povoados e rotas, porém, não suficiente para solucionar o "problema indígena". 
Por outro lado, Lozano fazendo juz ao seu lugar afirma que "Todo se facilitara, y allanará, si se lograrán las diligencias, que por parte de nuestra Compañía se hacen de continuo, para que vengan en admitir Missioneros Jesuítas" (Lozano, 1746,p. 6). Valorizando a ação missionária como um gesto perseverante frente à liberdade dos nativos, não deixava de ressaltar a promissora redução de Concepción de los Pampas. A escritura de Lozano coloca o trabalho jesuítico como a melhor solução, devendo ser praticado continuamente por compreender que "auque siempre costará mucho el reducirlos à vida politica, y racional [...] es el primer passo, para que les assiente bien la Fé” (Lozano, 1746, p. 6).

A marca sobre a escrita de Lozano também se deixa perceber na operação de sentido que busca construir. Oriundos de uma instituição que preza tanto a pobreza quanto a obediência, nada mais comum que procurassem se mostrar -através da suposta fala de um catecúmeno- como dóceis e amáveis (Lozano, 1746, p. 8), zelosos no trato com os gentis e fervorosos na lide espiritual. Se a guerra resolvia apenas parcialmente aquestão da segurança, o comprometimento dos jesuítas era apresentado como reconhecido até mesmo pelos nativos, exemplificado pela afirmação de que eram estes quem voluntariamente solicitavam a presença de missionários e povoados para viverem em redução. O valor de um jesuíta é exemplificado reiteradas vezes, seja pela sujeição a pedir esmolas para os a evangelização dos "bárbaros" (Lozano, 1746, p. 7), ou pela intervenção em casos de raptos, como, por exemplo, o do missionário que havia acolhido um menino cativo fugitivo $\mathrm{e}$ "vinieron los Barbaros armados à matar à ambos, $\mathrm{y}$ costo mucho ponerlos en razon, $\mathrm{y}$ hacerles desistir de fu perverso intento" (Lozano, 1746, p.8) aceitando o padre alegremente em pagar pelo resgate.

Apresentando-se como perseverantes, através do relato, os missionários legitimavam-se como o meio mais adequado para o trato com os indígenas, pois além de muito trabalharem para vencer a barbárie dos nativos, ainda precisavam vencer as suspeitas que sobre eles recaíam devido ao temor dos neófitos de acabarem como "Esclavos del Español" (Lozano, 1746, p. 7). Para Lozano o horror era justificado, pois muitos destes catecúmenos haviam muitas vezes presenciado "los malos exemplos de algunos malos Christianos" (Lozano, 1746, p. 8).

O fato de que Lozano compartilhava características em comuns a outros escritores, indicando uma certa homogeneidade entre os escribas da Companhia, pode ser sugerida a partir da mencionada carta duplicada, que foi anexada a que está em exame, através da qual o inaciano buscava prestar informações sobre a missão de índios pampas. Se por um lado, nela os índios são tidos por preguiçosos e vagabundos, por outro, a mávontade atribuída aos nativos exalta o labor missionário, que aos poucos lhes vão persuadindo $\mathrm{e}$ ensinando a doutrina. Segundo Manuel Garcia, autor dessa missiva, os "Caziques Serranos nos conocen, y tienen mucha estima de nostros, y cuentan allá en sus tierras (segun me dixo un cautivo Español) que los Padres de La Compañía son de buen [sic] corazon" (Garcia, apud Lozano, 1746, p. 17). De acordo com ele, as lideranças nativas "se fian de nosotros con seguridad, y sin rezelo, y han pedido varias veces Missioneros Jesuítas, para ir con ellos" (Garcia, apud Lozano, 1746, p. 17). Dizia Manuel Garcia que "Lo cierto es, que segun lo que sabemos, que eran al principio estos Indios, estan ya el dia de oy muy mejorados, y aun en los siete meses, que yo llevo aqui, he reconocido notable mudanza" (Garcia, apud Lozano, 1746, p. 19). 
Ao abordar a escrita jesuítica, a partir de Lozano e o historiógrafo que o sucedeu, Cagnel evidenciava que: no fundo toda [essa] escritura busca apresentar o trabalho missionário e o jesuíta como instrumentos da graça divina (2009, p. 305).Além de manter informado o Geral da Companhia de Jesus, a escrita jesuíta orientada à edificação de seus membros leitores comprometia-se ao mesmo tempo com a edificação da Instituição religiosa. O ponto de vista positivo sobre a atuação dos missionários edifica os ânimos dos demais colaboradores e também serve para contrastar os comportamentos dos sacerdotes com os dos demais espanhóis na região.

Organizados a partir da subjetividade de Lozano, o sentido dado aos acontecimentos permite constatar um discurso onde os religiosos são a melhor solução, embora o resultado de seus trabalhos somente seja perceptível em longo prazo. O sucesso militar não é descartado, e cumpre propósito argumentativo ao corroborar a existência de uma barbárie nativa a ser combatida, sobretudo, pela via religiosa.

\section{Considerações finais}

Para explicar a complicada relação evidenciada entre a Companhia, os jesuítas e seus textos, é necessário seguir duas linhas de intenções cujos sentidos encontram-se imbricados um ao outro -ainda que se deem em rumos diametralmente opostos. Por um lado, é preciso observar a relação no sentido da Ordem (como lugar de produção), o jesuíta -como escritor/construtor-, e o texto como um produto cuja existência é um meio eao mesmo tempo um fim. O escrito conduz a uma finalidade pois, como demonstrado, era produzido para servir como um testemunho de uma respectiva imagem, que o escritor ajudava a construir, motivo pelo qual também deve ser visto como um meio. Nesta direção, o texto é motivado pelos objetivos; ele não é a origem da intencionalidade que se busca, e,além de meio,tem fim em si mesmo, uma vez que também era feito para a posteridade. $\mathrm{O}$ escritor é o operador de um instrumento através do qual se almeja a representação de um ideal a ser lido para, então, ser construído. Deste modo, percebe-se que a Companhia é o lugar de produção de si mesma. Assim, como produto, isto é, uma representação ideal, também se encerra o outro sentido -motivo pelo qual os pontos de contato complexificam e dificultam o entendimento sobre esta tríplice relação. Por esta via, -Companhia/texto/jesuíta-, o escrito já não é mais o fim do plano de ação, mas sim o referencial de autoconstrução daquele que o escreve. Nesta circunstância, o texto se restringe a um instrumento. Assim, uma vez que em ambos os sentidos o texto se apresenta como meio de apropriação de seu conteúdo por parte do leitor, o redigido se tornava uma referência para todos a ser seguida. Desta forma, poder-se-ia considerá-lo também como um lugar? Me inclino a afirmar que não. Caso o fosse, não haveria distinção entre leitores e escritores. Seja por questão de habilidade ou envolvimento emocional com o conteúdo sobre o qual se é lido, entre os primeiros, são imensuráveis os níveis de apropriação. Já o escritor, sua relação é sempre mais profunda, poisao passo que aos outros informa, a si também se conforma. De modo geral, o jesuíta era também um produto da escrita, mais ainda quando ele mesmo a praticava, transformando-se em ícone da Ordem que representava. Ao se adequar ao 
molde inaciano, edificava-se a si mesmo, e através de si edificava a imagem que almejava representar. A Companhia era o lugar de produção, do texto, de si, e de seus membros.

\section{Notas}

1. Esta pesquisa foi originalmente desenvolvida como trabalho de conclusão para a disciplina "La Compañia de Jesús em América colonial española y su escritura etnológica", ministrada pelo professor doutor Carlos Daniel Paz (FCH-UNCPBA), na Universidade do Vale do Rio dos Sinos (UNISINOS), no ano de 2016. Agradeço a leitura e o parecer do professor, cujas sugestões -humilde e modestamente-me propusa corresponder.

2. Mesmo que diversas vezes essa pareça estar vinculada ao âmbito das tentações (Loyola, [1553-1555], capítulo VIII, \$82).

3. Para o auxílio da leitura, nas citações oriundas das Reglas, aonde originalmente se encontra a letra "f" -largamente utilizada nos escritos de Lozano- mas que exprimia o som de "s", os signos foram atualizados, conforme se escreve atualmente.

4. Para o auxílio da leitura, nas citações utilizadas, aonde originalmente se encontra a letra "f" -largamente utilizada nos escritos de Lozano- mas que exprimiam o som de "s", os signos foram atualizados, conforme se escreve atualmente.

\section{Fontes}

Loyola, I. de. S. J. [1553-1555]. Autobiografía de San Ignacio de Loyola. Texto recogido por el Pe. Luis Gonçalves da Camara entre 1553 y 1555. Disponível em:<https://www. ebookscatolicos.com/descargas/descargar-pdf-autobiografia-san-ignacio-de-loyola/ $>$. Acesso em: 20/12/2016.

Loyola, I. de. S.J. [1599] Constituciones de la Compañia de Jesús. 1599. Disponível em: < http://www.documentacatholicaomnia.eu/03d/1491-1556,_Ignatius_Loyola,_Constitu ciones_de_la_Compania_de_Jesus,_ES.pdf $>$. Acesso em: 24/12/2015.

Lozano, P. de. S.J. [01/11/1746]. Carta del P. Pedro Lozano, de la Compañia de Jesus, de la Provincia del Paraguay, escrita ao P. Bruno Morales, de la misma Compañia, y Provincia, existente en esta Corte de Madrid. Córdoba, 1746.

REGLAS [1735]. Reglas de la Compañia de Jesus, y la Carta de la obediencia de nuestro glorioso padre San Ignacio, Formulas de los votos, y documentos del mismo Santo Padre, 1735. Disponível em: <http://www.memoriachilena.cl/602/w3-article-8042.html $>$. Acesso em 22/12/2016.

\section{Referências Bibliográficas}

Cargnel, J. G. (2009). La Historia de la conquista en las versiones de Pedro Lozano y José Guevara. Estudios comparados de la producción escrita de la Compañia de Jesús en el siglo XVIII. História Unisinos, vol. 13, no 3 - setembro/dezembro, p. 297-307. 
Cargnel, J. G. (2007). Pedro Lozano S.J., un historiador oficial. Projeto História, no 35, dez., p. 315-323.

Cargnel, J. G. (2010). Reflejos del patronato en el historiador jesuíta Pedro Lozano S.J. Folia Histórica del Nordeste, no 18., p. 97-111.

Certeau, Michel de. (2015). A escrita da história. 3ed. Rio de Janeiro: Forense.

Dominguez, B. H.; Santos, Breno Machado dos. (2009). Sob o signo das Luzes: o pensamento jesuítico e a Ilustração nas cartas do Padre David Fáy. História Unisinos, vol. 13, no 3 - setembro/dezembro, p. 233-240.

Fleckl, E.; Franzen, B.; Martins, M. C. B. (Orgs.) (2008). Carta Ânua da Província Jesuítica do Paraguai 1659-1662. São Leopoldo, RS: Oikos; Unisinos; Cuiabá, MT: EdUFMT.

Londoño, F. T. (2002). Escrevendo Cartas. Jesuítas, Escrita e Missão no século XVI. Revista Brasileira de História. São Paulo, vol. 22, no 43, p. 11-32.

Martins, M.C. B. (2014). Jesuítas e índios nas “missões austrais": Uma experiência na pampa argentina (século XVIII). Revista História e Cultura, Franca-SP, vol. 3, no 2, p. 233-249.

Mayo, C. A. (1998). Terratenientes, soldados y cautivos. La Frontera, 1736-1815. Buenos Aires. Editora: Biblos.

São Bento, V. M. C. (2015). A escrita jesuítica e suas práticas: ciência e produção de medicamentos através da Colecção de Varias Receitas de 1766. XXVIII Simpósio Nacional de História: Lugares dos historiadores: velhos e novos desafíos. Florianópolis, p. 01-11. Disponível em: <http://www.snh2015.anpuh.org/resources/anais/39/1437085988_AR QUIVO_TextoANPUH_Asdiversasformasdaescritajesuita.pdf $>$. Acesso em: 15/11/2018.

Tavares, C. C. da Silva (2005). A escrita jesuítica da história das missões no Estado do Maranhão e Grão-Pará (século XVII). Actas do Congresso Internacional Espaço Atlântico de Antigo Regime: poderes e sociedades, p. 01-09. Disponível em: $<$ http://cvc.institutocamoes.pt/eaar/coloquio/comunicacoes/celia_tavares.pdf > . Acesso em: 15/11/2018.

Wucherer, P. M. O. Svriz. (2013). Un documento inédito delsiglo XVIII. El padre jesuita Pedro Lozano y suprimera Carta Anua, 1720-1730. Hispania Sacra, LXV, 131, enerojunio, p. 139-159.

Resumen: Este trabajo se propone examinar la práctica de la escritura de Pedro Lozano, un jesuita que ejerció la función de historiógrafo en la Compañía de Jesús, a mediados del siglo XVIII. La reflexión fue realizada a partir de una misiva que él destino al Procurador General, Padre Bruno Morales. Se sabe que la documentación producida por los ignacianos posee un reconocido valor histórico y etnográfico, siendo, por ello, explorada por los investigadores de un modo recurrente, así como por escritores ajenos al medio académico de la historia. Un análisis sobre este tipo de documentación permite, además, considerar como objeto la práctica de la escritura de aquellos individuos, sobretodo, a partir de la reflexión de su "lugar de producción", así como de aquella “operación historiográfica" en ella empleada, tal y como lo sugirió Michel de Certeau. De ese modo, no ignorando la existencia de una individualidad en la escritura de Lozano se definió - para circunscribir el lugar desde dónde él escribe así como para delimitar la actividad escrituraria en sí- deli- 
near los límites impuestos por la Orden a la escritura a partir de un examen de las Reglas de la Compañía de Jesús, de las Constituciones y de la autobiografía de San Ignacio de Loyola. De modo simultáneo con en el relato de los acontecimientos reales, y haciendo uso de una representación cuya constante era la tensión social, se organizaba un discurso desarrollado a partir de reiteradas orientaciones sobre el escribir. Éstas, expresadas en las Cartas, y supuestamente obedecidas, al tornarse práctica de lectura y de escritura, al mismo tiempo que informaban, también conformaban una idea precisa sobre lo descripto y sobre el autor del escrito. Edificaban una imagen institucional aunque también daba por resultado una construcción propia del autor de las mismas. Al mismo tiempo que las Cartas edificaban, también se identificaba a los autores pudiendo así conocer a la Orden por el individuo así como por las prácticas del mismo.

Palabras clave: Lugar de producción - Jesuitas - Práctica de la escritura.

Abstract: This paper aims to examine the practice of the writing of Pedro Lozano, a Jesuit who served as a historiographer in the Society of Jesus, in the mid-eighteenth century. The reflection was made from a letter that he sent to the Attorney General, Father Bruno Morales. It is known that the documentation produced by the Ignatians possesses a recognized historical and ethnographic value, being, therefore, explored by researchers in a recurrent way, as well as by writers alien to the academic milieu of history. An analysis of this type of documentation also allows to consider as an object the practice of the writing of those individuals, above all, from the reflection of their "place of production", as well as that "historiographical operation" employed in it, as suggested by Michel de Certeau. Thus, not ignoring the existence of an individuality in the writing of Lozano was defined -to circumscribe the place from where he writes as well as to delimit the writing activity itself- delineate the limits imposed by the Order on writing from an examination of the Rules of the Society of Jesus, of the Constitutions and of the autobiography of Saint Ignatius of Loyola. Simultaneously with the story of real events, and making use of a representation whose constant was social tension, a discourse developed from repeated orientations on writing was organized. These, expressed in the Letters, and supposedly obeyed, by becoming a practice of reading and writing, at the same time as they informed, also conformed an accurate idea about what was described and about the author of the writing. They built an institutional image although it also resulted in a construction of the author's own. At the same time that the Letters were building, the authors were also identified, thus being able to know the Order by the individual as well as by the practices of the same.

Keywords: Production place - Jesuits - Writing practice.

[Las traducciones de los abstracts fueron supervisadas por el autor de cada artículo] 